\title{
The Method of Quadratic Combination Weighting Fuzzy Comprehensive Evaluation applied in Water Quality Assessment
}

\author{
Pan Jun \\ Shen Yang Jianzhu University \\ School of Municipal and Environment Engineering \\ Shen Yang, China \\ pan100jun@263.net
}

\author{
Meng Li, Zhong Zhen \\ Shen Yang Jianzhu University \\ School of Municipal and Environment Engineering \\ Shen Yang, China \\ Meng100li@sina.com
}

\begin{abstract}
For the shortcoming of Fuzzy Comprehensive Evaluation Method such as subjectivity and lacking of information more, in order to improve the index weight's scientific and accuracy. In this paper, based on the application of AHP and entropy weight method, fuzzy comprehensive evaluation obtained quadratic combination weight of each index method, four dry season water quality of the study area monitoring sections were evaluated. The results showed that this method avoided the subjective differences of expert score method, meeting target weight and the effective degree of credibility. It is suggested that the method of quadratic combination weighting fuzzy comprehensive evaluation is scientific, accurate, objective, it could be widely applied in water quality assessment.
\end{abstract}

Keywords-groundwater; water quality assessment; fuzzy comprehensive evaluation; quadratic combination weighting

\section{INTRODUCTION}

Groundwater evaluation method [1] variety, mainly fuzzy comprehensive evaluation method, gray relational analysis, artificial neural networks, fuzzy comprehensive evaluation method for its systematic, clear, you can solve the fuzzy and difficult to quantify the characteristics of the problem has been widely applied.

\section{The SeCond Combination Weighting FuZZY COMPREHENSIVE EVALUATIONMODEL}

\section{A. AHP Seeking Quality Index Weights Each}

AHP [2] is to be evaluated in accordance with the logic of the system to evaluate the indicators form an ordered hierarchy. Then on the same floor or in the same domain indicators pairwise comparison, according to the provisions of scale value construct comparative judgment matrix. Then calculate the maximum comparative judgment matrix eigenvalues and corresponding eigenvectors, and the feature vector normalization, and finally get the weight of each indicator.

\section{B. Entropy Method for Each Water Quality Index Weights}

Entropy value reflects the utility value of the index information, with the entropy method [3] calculated index weights. In the judgment of the evaluation matrix based on normalized treatment to obtain the normalized judgment matrix, determine the evaluation index entropy. The final calculation of the weight of each index value. Greater reliability of the method, adaptive function, suitable for samples with data.

\section{Second of Each Indicator to Obtain the Optimal Portfolio Weights}

Empowerment is a combination of two or combination of two kinds of methods for empowering the results obtained, the combination of empowerment can effectively improve the accuracy of the weight assignment. In this paper, A secondary combination weighting [4] approach: in AHP and entropy weight method, based on the weight of processing, depending on the target weight and the weight of the principle of minimum deviation, construct nonlinear optimization model and solution of quadratic optimal portfolio weights obtained $\mathrm{W} *$. The fuzzy comprehensive evaluation with fuzzy relation matrix for computing, and finally get to see the whole thing been assessed on the quality levels of membership.

\section{Quadratic Combination Weighting Fuzzy Comprehensive} Evaluation of calculation steps

Step 1: Determine the factors evaluated, that evaluation of $\mathrm{m} \mathrm{U}=\left\{\mathrm{u} \_1, \mathrm{u} \_2, \mathrm{u} \_3 \ldots \mathrm{u} \_\mathrm{m}\right\}$;

Step2: Determine the evaluation level, $V=\left\{v_{-} 1, v_{-} 2\right.$, v_3 $\ldots$ v_n $\}$;

Step3: Perform single factor evaluation, fuzzy relationship matrix R;

In the constructor of the class fuzzy subset, the assessment should be things one by one from each factors to quantify, determined from the single factor was rated things look fuzzy subset for each class of membership (R/ui), then get fuzzy relationship matrix.

Step 4: by AHP and entropy method to get the weight according to the following formula for computing;

$$
\left\{\begin{array}{c}
w i=\frac{w 1 i * w 2 i}{\sum_{i=1}^{\mathrm{n}} \mathrm{w} 1 \mathrm{i} * \mathrm{w} 2 \mathrm{i}} \\
w i=\frac{1}{2}(w 1 \mathrm{w}+\mathrm{w} 2 \mathrm{i})
\end{array}\right.
$$

Get a second combination weight vector $\mathrm{W} 1=\left(\mathrm{w} 1^{(1)}\right.$, $\left.\mathrm{w} 2^{(1)}, \mathrm{w}^{(1)} \ldots \mathrm{wn}^{(1)}\right)$ and $\mathrm{w} 2=\left(\mathrm{w} 1^{(2)}, \mathrm{w}^{(2)}, \mathrm{w}^{(2)} \ldots \mathrm{wn}^{(2)}\right)$ vector;

Step 5: Construct the optimal combination of weight

$$
\mathrm{W}^{*}=\left(\mathrm{w}_{1} * \mathrm{w}_{2} * \mathrm{w}_{3} * \ldots \ldots . . \mathrm{w}_{\mathrm{n}} *\right)
$$




$$
\begin{gathered}
\sum_{\mathrm{i}=1}^{\mathrm{n}} \mathrm{wi}=1(\mathrm{i}=1,2,3 \ldots \ldots \mathrm{n}) \\
\mathrm{W}^{*}-\mathrm{W}^{1}=\left(\mathrm{w}_{1} *-\mathrm{w} 1^{(1)}, \mathrm{w}_{2} *-\mathrm{w} 2^{(1)},\right. \\
\left.\mathrm{w}_{3} *-\mathrm{w} 3^{(1)} \ldots \mathrm{w}_{\mathrm{n}}{ }^{*}-\mathrm{wn}^{(1)}\right) \\
\mathrm{W}^{*}-\mathrm{W}^{2}=\left(\mathrm{w}_{1} *-\mathrm{w} 1^{(2)}, \mathrm{w}_{2}{ }^{*}-\mathrm{w} 1^{(2)},\right. \\
\left.\mathrm{w}_{3}{ }^{*}-\mathrm{w} 1^{(2)} \ldots \mathrm{w}_{\mathrm{n}}{ }^{*}-\mathrm{wn}^{(2)}\right)
\end{gathered}
$$

Step 6: According to goal weight and the weight of the principle of minimum deviation, nonlinear optimization model is constructed as follows(2)

$$
\left\{\begin{array}{c}
\min \sum_{\mathrm{k}=1}^{2}\left\|\mathrm{~W} *-\mathrm{W}^{\mathrm{k}}\right\|=\min \sum_{\mathrm{k}=1}^{2} \sum_{\mathrm{i}=1}^{\mathrm{n}}\left(\mathrm{wi} *-\mathrm{wi}^{\mathrm{k}}\right) \\
\text { s.t. } \sum_{\mathrm{i}=1}^{\mathrm{n}} \mathrm{wi}=1
\end{array}\right.
$$

Step 7: Solving the nonlinear optimization model; Lagrangian function constructor

$$
\begin{aligned}
\mathrm{L}\left(\lambda_{1}, \lambda_{2}, \mathrm{M}\right)= & \sum_{\mathrm{k}=1}^{2} \sum_{\mathrm{i}=1}^{\mathrm{n}}\left(\lambda_{1} \mathrm{wi}+\lambda_{2} \mathrm{wi}-\mathrm{wik}\right)^{2} \\
& +\mathrm{M}\left(\sum_{\mathrm{i}=1}^{\mathrm{n}} \mathrm{wi}-1\right)
\end{aligned}
$$

Respectively $\lambda \_1, \lambda \_2, M$ seeking an order partial derivatives equal to zero and optimized conditions expressed in the form of a matrix,

$$
\begin{gathered}
{\left[\begin{array}{l}
\mathrm{W}(1)(\mathrm{W}(1)) \mathrm{T}+\mathrm{W}(1)(\mathrm{W}(2)) \mathrm{T} \\
\mathrm{W}(2)(\mathrm{W}(1)) \mathrm{T}+\mathrm{W}(2)(\mathrm{W}(2)) \mathrm{T}
\end{array}\right]\left[\begin{array}{l}
\lambda_{1} \\
\lambda_{2}
\end{array}\right]} \\
=\left[\begin{array}{l}
\mathrm{W}(1)(\mathrm{W}(1)) \mathrm{T} \\
\mathrm{W}(2)(\mathrm{W}(2)) \mathrm{T}
\end{array}\right]
\end{gathered}
$$

Transformed into equations of the form

$$
\left\{\begin{array}{l}
\lambda_{1} \mathrm{~W}(1)(\mathrm{W}(1)) \mathrm{T}+\lambda_{2} \mathrm{~W}(1)(\mathrm{W}(2)) \mathrm{T}=\mathrm{W}(1)(\mathrm{W}(1)) \mathrm{T} \\
\lambda_{1} \mathrm{~W}(2)(\mathrm{W}(1)) \mathrm{T}+\lambda_{2} \mathrm{~W}(2)(\mathrm{W}(2)) \mathrm{T}=\mathrm{W}(2)(\mathrm{W}(2)) \mathrm{T}
\end{array}\right.
$$

Solved $\lambda_{1}, \lambda_{2}$ values into the above equation, can be obtained quadratic optimal combination weight $\mathrm{W}^{*}$.

\section{ApPlication EXAMPLES}

\section{A. Assessment and Evaluation to Determine the Cross- Section}

This paper selects Lalatun, Xiaobaima, Xiguan, Cishan four monitoring sections for the study According to the monitoring data of groundwater quality, select Fluoride $\left(\mathrm{F}^{-}\right)$, Total dissolved solids(TDS), Permanganate index $\left(\mathrm{COD}_{\mathrm{Mn}}\right)$, The total hardness(TH), Sulfate $\left(\mathrm{SO}_{4}{ }^{2-}\right), \quad$ Chloride $\left(\mathrm{Cl}^{-}\right)$, Ammonia $\left(\mathrm{NH}_{4}{ }^{+}\right)$seven indicators as an evaluation factor. Taking into account seasonal variations in groundwater quality with little, therefore, the water quality of its dry season water quality assessment. Specific information in the following table:

TABLE I. DRy SEASON WATER QUALITY TEST RESULTS OF THE
MONITORING SECTION(mg/L)

\begin{tabular}{|c|c|c|c|c|}
\hline location & Lalatun & Xiaobaima & Xiguan & Cishan \\
\hline F- & 0.15 & 0.23 & 0.26 & 0.22 \\
\hline TDS & 691 & 358 & 1474 & 986 \\
\hline CODMn & 2.57 & 1.8 & 2.37 & 1.11 \\
\hline TH & 100.57 & 72.63 & 362.16 & 111.78 \\
\hline SO42- & 260.11 & 69.93 & 62.25 & 168.86 \\
\hline $\mathbf{C l}^{-}$ & 160.97 & 185.65 & 283.11 & 210.23 \\
\hline $\mathbf{N H}_{4}^{+}$ & 0.02 & 0.02 & 0.02 & 0.02 \\
\hline
\end{tabular}

TABLE II. GROUNDWATER QUALITY GRADING STANDARDS $(\mathrm{GB} / \mathrm{T} 14848-93)(\mathrm{mg} / \mathrm{L})$

\begin{tabular}{|c|c|c|c|c|c|}
\hline Index & I & II & III & IV & V \\
\hline $\mathbf{F}^{-}$ & 1 & 1 & 1 & 2 & $\geq 2$ \\
\hline TDS & 300 & 500 & 1000 & 2000 & $\geq 2000$ \\
\hline $\mathbf{C O D}_{\mathbf{M n}}$ & 1.0 & 2.0 & 3.0 & 10 & $\geq 10$ \\
\hline $\mathbf{T H}$ & 150 & 300 & 450 & 550 & $\geq 550$ \\
\hline $\mathbf{S O}_{\mathbf{4}}{ }^{2-}$ & 50 & 150 & 250 & 350 & $\geq 350$ \\
\hline $\mathbf{C l}^{-}$ & 50 & 150 & 250 & 350 & $\geq 350$ \\
\hline $\mathbf{N H}_{4}{ }^{+}$ & 0.02 & 0.02 & 0.2 & 0.5 & $\geq 0.5$ \\
\hline
\end{tabular}

B. Afiliation Fuzzy Evaluation Matrix to Determine

According to the membership function of fuzzy comprehensive evaluation and a given quality grading standards. Determine the evaluation index for the degree of membership of each grading get affiliation matrix as follows:

$$
\begin{gathered}
\text { Lalatun } \\
\mathrm{R}=\left[\begin{array}{ccccc}
1 & 0 & 0 & 0 & 0 \\
0 & 0.62 & 0.38 & 0 & 0 \\
0 & 0.43 & 0.57 & 0 & 0 \\
1 & 0 & 0 & 0 & 0 \\
0 & 0 & 0.85 & 0.15 & 0 \\
0 & 0.65 & 0.35 & 0 & 0 \\
1 & 0 & 0 & 0 & 0
\end{array}\right] \mathrm{R}=\left[\begin{array}{ccccc}
1 & 0 & 0 & 0 & 0 \\
0.27 & 0.73 & 0 & 0 & 0 \\
0.20 & 0.80 & 0 & 0 & 0 \\
1 & 0 & 0 & 0 & 0 \\
0.30 & 0.70 & 0 & 0 & 0 \\
0 & 0.84 & 0.16 & 0 & 0 \\
1 & 0 & 0 & 0 & 0
\end{array}\right]
\end{gathered}
$$

$$
\text { Xiguan }
$$

$$
\mathrm{R}=\left[\begin{array}{ccccc}
1 & 0 & 0 & 0 & 0 \\
0 & 0 & 0.53 & 0.47 & 0 \\
0 & 0.63 & 0.37 & 0 & 0 \\
0 & 0.59 & 0.41 & 0 & 0 \\
0.88 & 0.12 & 0 & 0 & 0 \\
0 & 0 & 0.67 & 0.33 & 0 \\
1 & 0 & 0 & 0 & 0
\end{array}\right] \mathrm{R}=\left[\begin{array}{ccccc}
1 & 0 & 0 & 0 & 0 \\
0 & 0.03 & 0.97 & 0 & 0 \\
0.59 & 0.41 & 0 & 0 & 0 \\
1 & 0 & 0 & 0 & 0 \\
0 & 0.61 & 0.39 & 0 & 0 \\
0 & 0.30 & 0.70 & 0 & 0 \\
1 & 0 & 0 & 0 & 0
\end{array}\right]
$$

\section{The Evaluation Factors to Determine the Optimal Weight Vector}

Examples of each index entropy calculations to the data, for example Lara Tun dry season. According to Table 1 in the measured value of each indicator, establishing the initial concentration matrix evaluation indicators are negative indicators that the smaller the value corresponding to the measured water quality is better. Poor initial matrix normalized then using the standardized approach to treat the data in Table 1 to obtain standardized matrix. The results are as follows: 
TABLE III. THE WATER QUALITY OF GROUNDWATER AND THE INFORMATION ENTROPY WEIGHTS

\begin{tabular}{|c|c|c|}
\hline Index & Information entropy & Weights \\
\hline $\mathbf{F}^{-}$ & 0.24 & 0.134 \\
\hline TDS & $2.5 \times 10^{-4}$ & 0.179 \\
\hline $\mathbf{C O D}_{\mathbf{M n}}$ & 0.12 & 0.155 \\
\hline $\mathbf{T H}$ & $1.2 \times 10^{-3}$ & 0.177 \\
\hline $\mathbf{S O}_{\mathbf{4}}{ }^{2-}$ & $2.0 \times 10^{-3}$ & 0.174 \\
\hline $\mathbf{C l}^{-}$ & $1.7 \times 10^{-3}$ & 0.175 \\
\hline $\mathbf{N H}_{\mathbf{4}}{ }^{+}$ & 0.97 & 0.006 \\
\hline
\end{tabular}

In Water Quality Assessment, To determine the index weights of evaluation results is essential. As a result of the impact on water quality evaluation is different, therefore it should be given different weights. The same data as an example to LalaTun, to a single factor pollution index method for processing the raw data.

\section{$\mathrm{Pi}=\mathrm{Ci} / \mathrm{Si}$}

Ci-the measured concentration; Si-the standard concentration

Computer programming using MATLAB software to get the maximum discriminant matrix eigenvalue and eigenvector. In this case, the weight vector

$$
\left(\begin{array}{lllllll}
0.060 & 0.293 & 0.255 & 0.123 & 0.085 & 0.148 & 0.036
\end{array}\right)^{\mathrm{T}}
$$

According to equation (2) to obtain equations are

$$
\left\{\begin{array}{l}
0.217 \lambda_{1}+0.188 \lambda_{2}=0.217 \\
0.188 \lambda_{1}+0.173 \lambda_{2}=0.173
\end{array}\right.
$$

Solution was $\lambda_{1}=0.643 \quad \lambda_{2}=0.403$

To enable $\lambda_{1}+\lambda_{2}=1$, Were weighted to obtain

$$
\lambda_{1}{ }^{*}=0.615 \quad \lambda_{2}{ }^{*}=0.385
$$

Then get the optimal weights evaluation The results as follows:

\section{Evaluation Results}

The resulting optimal weight and fuzzy relationship matrix synthesis calculations, geting the water quality objectives fuzzy comprehensive evaluation result vector $\mathrm{B}$, As follows.

TABLE IV. The Evaluation of The Optimal Weigh

\begin{tabular}{|c|c|}
\hline Index & Optimal weight \\
\hline $\mathbf{F}^{-}$ & 0.067 \\
\hline TDS & 0.290 \\
\hline $\mathbf{C O D}_{\mathbf{M n}}$ & 0.208 \\
\hline $\mathbf{T H}$ & 0.141 \\
\hline $\mathbf{S O}_{4}{ }^{2-}$ & 0.180 \\
\hline $\mathbf{C r}^{-}$ & 0.105 \\
\hline $\mathbf{N H}_{4}{ }^{+}$ & 0.009 \\
\hline
\end{tabular}

TABLE V. THE EVALUATION RESUlTS OF WATER QUALITY MONITORING SECTIONS

\begin{tabular}{|c|c|c|c|c|}
\hline Membership & Lala-tun & Xiao-baima & Xi-guan & Ci-shan \\
\hline level I & 0.217 & 0.349 & 0.195 & 0.277 \\
\hline level II & 0.337 & 0.62 & 0.215 & 0.253 \\
\hline levelIII & 0.419 & 0.03 & 0.412 & 0.47 \\
\hline levelIV & 0.027 & 0 & 0.178 & 0 \\
\hline levelV & 0 & 0 & 0 & 0 \\
\hline level & III & II & III & III \\
\hline Complex Index & Better & Good & Better & Better \\
\hline
\end{tabular}

\section{E. Analysis}

The evaluation results of the above table it can be seen, Little white Ishimura's Class II water quality, The remaining three are the three types of water monitoring sections, and comprehensive index evaluation results are compared, basically the same, This method is suitable for visible water quality assessment and has a certain rationality.

\section{CONCLUSION}

Evaluation of groundwater chloride and high levels of total dissolved solids, mainly because the assessment area is located in the outskirts of agriculture Huludao City, various regional distribution of agricultural irrigation and farm. Rainfall after fertilization of agricultural residues and dung fertilizer and pesticide wastewater will seep into the aquifer with rainwater, the groundwater chloride and dissolved solids content increased.

Using of secondary combination weighting fuzzy comprehensive evaluation model to evaluate the groundwater quality, accurate and objective evaluation results. The calculation of this case, Groundwater Quality Evaluation open to new ideas, Water Quality Assessment also has certain reference significance.

\section{REFERENCES}

[1] Wang Lijuan, PAN Jun, Yang Xin, Han Chunyang. Three kinds of water quality evaluation method comparative analysis [J]. Groundwater, 2011,33 (3) :103-104

[2] Lu Wenxi, Liddy, Zhang Lei, Iraq Yanping Based on AHP Fuzzy Comprehensive Evaluation in Water Quality Assessment [J]. Irrigation. 2011 (03)

[3] Yangkai Yun, Wang Liang, Zhu Feng, Feng Wei. Improved Entropy Weight Fuzzy Evaluation Model in hydraulic engineering application [J]. Irrigation 2007 (08)

[4] ROCKETS; based on a combination of empowerment secondary college financial risk evaluation index weightsmeasured Accounting Education Research 201205

[5] Pengzhao Liang, HE Bin, PENG Yong, LIANG Guo-hua, Wang Zairu, Wang Guoli. Based on entropy weight variable fuzzy model in underground water quality evaluation [J]. Water Resources and Water Engineering. 2010 (04)

[6] Tie wind, Pan Xiaohui. Entropy Fuzzy Mathematics Method in Water Quality Assessment [J]. Shanxi Architecture. 2010 (14)

[7] Tian Zhihui, GAO Sheng Chao. Based on Entropy Weight Fuzzy Comprehensive Evaluation in Surface Water Quality Evaluation [J]. Anhui Normal University (Natural Science Edition). 2012 (01)

[8] Tian Hong, Yang Jing. Improved AHP and fuzzy comprehensive evaluation coupled model for water quality evaluation $[\mathrm{J}]$. Environmental Sciences 2011 (01) 
[9] Li, Lu Wenxi, Caoming Zhe, Li Ping. Principal Component Analysis in Changchun City Shitoukoumen Water Environment Quality Evaluation [J]. Irrigation 2009 (01)

[10] Xu Ligang, Ye Chang, Zhang Qi, JIANG Jia-hu, high Seahawks based on fuzzy pattern recognition Comprehensive Evaluation of Groundwater Quality [J]. Hydrogeology and Engineering Geology. $2011(05)$

[11] Yin Jing Zhang, Fu Jing, Xie camp, kill Victoria East, Loud.
Improved Fuzzy Evaluation Method in Dezhou Groundwater Quality Evaluation [J]. Harness. 2010 (12)

[12] Huer Yan Based on Entropy Weight Fuzzy Comprehensive Evaluation Method of Water Quality [J]. Scientific information. 2011 (16)

[13] Section Chunxiang, Wang Quanrong. Fuzzy comprehensive evaluation in groundwater quality evaluation and characteristics analysis [J]. Huaihua University (Natural Science) 2008 (03) 